\title{
Pasif Radar Uygulamalarında Çoklu Ardıșı OFDM Kanalı Kullanımının Menzil Çözünürlüğüne Etkilerinin İncelenmesi
}

\author{
Effects of the Successive Multiple OFDM Channels on Range Resolution in Passive Radar \\ Applications
}

Büşra KARANFIL ${ }^{1, a}$, Burak TÜYSÜZ ${ }^{*}, 1, \mathrm{~b}$

${ }^{1}$ Recep Tayyip Erdoğan Üniversitesi, Elektrik Elektronik Mühendisliği Bölümü, 53100, Rize

\author{
• Geliş tarihi / Received: 04.01.2019 • Düzeltilerek geliş tarihi / Received in revised form: 21.08.2020 • Kabul tarihi / Accepted: 19.09.2020
}

\begin{abstract}
Öz
Uzaktan cisim tespiti ve takibi yapabilen sistemlerin performansını artırmak, kapsama alanını genişletmek ve maliyetini azaltmak için birçok çalışma yapılmaktadır. Pasif radar sistemleri kapsama alanını maliyet etkin olarak arttırabilmek için iyi bir seçenektir. Pasif radarlar, kendilerine ait vericisi bulunmayan ancak ortamda hali hazırda var olan ticari vericileri kullanarak hedef tespit ve takibi yapan sistemlerdir. Bununla birlikte sistemlerin hedef tespit performansı kullanılan ticari vericinin sinyal özelliklerine göre değişmektedir. Sistemlerin integrasyon zamanına bağlı olarak Doppler çözünürlüğü değiştirilebilirken, menzil çc̈zünürlüğü sinyalin bant genişliğine bağlı olarak değişmektedir. Bu makalede, OFDM sinyallerini kullanan pasif radar sistemlerinde çoklu ardışı OFDM kanalı kullanımının menzil çözünürlüğüne etkileri incelenmiştir. Öncelikle OFDM tabanlı bir sinyalin benzetimi yazılım tabanlı radyo ile yapılmıştır ve öz-belirsizlik fonksiyonu analiziyle bu sinyalin menzil çözünürlüğü özellikleri incelenmiştir. Ardından ardışık kanallar eklenerek özbelirsizlik fonksiyonu analiz edilmiş ve menzil çözünürlüğündeki değişimler gözlemlenmiştir. Ardışık beş OFDM kanalı kullanıldı̆̆ında menzil çözünürlüğünün korelatif özelliklerini kaybetmeden $\% 48$ oranında iyileştirilebileceği gözlemlenmiştir.
\end{abstract}

Anahtar kelimeler: Belirsizlik Fonksiyonu, Menzil Çözünürlüğü, OFDM, Pasif Radar, Yazılım Tabanlı Radyo

\begin{abstract}
Studies are carried out to increase the performance of the systems that can perform remote object detection and tracking, to extend the coverage area and to reduce the cost. Many passive radar systems are a good candidate for cost-effective coverage. Passive radar systems are capable of target detection and tracking using commercially available commercial donors without their own transmitter. However, the target detection performance of the systems varies according to the signal characteristics of the commercial transmitter used. While the Doppler resolution of the systems can be changed depending on the integration time, the range resolution varies depending on the bandwidth of the signal. In this article, the effects of multiple consecutive OFDM channel usage on range resolution were investigated in passive radar systems using OFDM signals. First of all, using a software-based radio, an OFDM-based signal was simulated and the range resolution characteristics of this signal were analyzed by self-uncertainty function analysis. Then, sequential channels were added to analyze the self-uncertainty function and changes in range resolution were observed. Since five consecutive channels were used, it was observed that the range resolution could be improved by $42 \%$ without losing the correlative properties.
\end{abstract}

Keywords: Ambiguity Function, OFDM, Passive Radar, Range Resolution, Software Defined Radio

\footnotetext{
*b Burak TÜYSÜZ, burak.tuysuz@erdogan.edu.tr, Tel: (0464) 22375 18, orcid.org/0000-0002-2053-3715

${ }^{a}$ orcid.org/0000-0001-7088-2553
} 


\section{Giriş}

Gelişen teknolojiyle birlikte kablosuz cihaz kullanımı gün geçtikçe artmaktadır. Bu cihazlardan yayılan sinyaller frekans spektrumunda doluluğa sebep olmanın yanı sıra çevre ve insan sağlı̆̆ını da olumsuz etkileyebilmektedir (Tüysüz ve Mahmutoğlu, 2017). Bu sebeple mevcut kablosuz vericiler kullanılarak yapılan hedef tespit ve takip uygulamaları büyük önem taşımaktadır. $\mathrm{Bu}$ sistemlere en iyi örnek olarak bistatik radarların bir alt kolu olan pasif radarlar verilebilir. Bistatik radarlar, alıcı ve aydınlatıcı antenlerini farklı coğrafik konumlarda bulunduran sistemlerdir. $\mathrm{Bu}$ sistemlerde hedef tespiti, aydınlatıc sinyalin hedef üzerinden yansıması ve bu yansımanın alıcı sistem tarafindan izlenmesi ile yapılır. Bistatik radarların başlıca avantajları şunlardır. Alıcı sistem tamamen pasif durumda olduğu için konumu ve özellikleri tespit edilemez aynı zamanda alıcı sisteminin pasif olması maliyeti düşürür. $\mathrm{Bu}$ sistemler, hayalet uçaklara karşı daha dirençlidir, hayalet uçaklar yapıs1 gereği radar 1şınlarını bistatik yöne doğru dağıtacaktır (Griffiths ve Baker, 2005a). Ayrıca mono statik radarı yenmek için geliştirilen teknolojiye karşı koymaktadırlar. Pasif radarlar ise kendisine ait vericisi olmayan ancak konumlandırıldığı ortamdaki vericileri kullanarak hedef tespit ve takibi yapabilen sistemlerdir (Tüysüz, 2018). Pasif radarlar ortamda bulunan kablosuz bağlantı alanı (Wi-Fi), küresel konumlama sistemi (GPS), mobil iletişim küresel takip sistemi (GSM), televizyon, radyo gibi vericilere ait sinyalleri kullanarak hedef tespit ve takibi yapabilmektedir (Lauri vd., 2007; Colone vd., 2012; Brisken vd., 2017; Milani vd., 2018). Bu sebeple tespit edilmeleri zordur ve gizlilik gerektiren hedef tespit ve takip uygulamalarında kullanılabilirler. $\mathrm{Bu}$ sistemler en temel haliyle ticari bir verici, bir referans anteni ve bir eko anteninden oluşmaktadırlar. Pasif radar sistemine ait en genel geometri Şekil 1'de verilmiştir. Şekilden de görülebileceği gibi referans anteni vericiden yayılan sinyalleri toplamakla görevlidir. Vericiden yayılan sinyallerin hedeften yansiyan kopyaları ise sistemde bulunan bir diğer anten olan eko anteni tarafindan toplanmaktadır. $\mathrm{Bu}$ sistemlerde hedef tespit ve takibi, referans anteni ve eko anteni tarafindan toplanan sinyallerin karşılaştırılmasıyla yapılabilmektedir (Berger vd., 2010; Tüysüz vd., 2013).

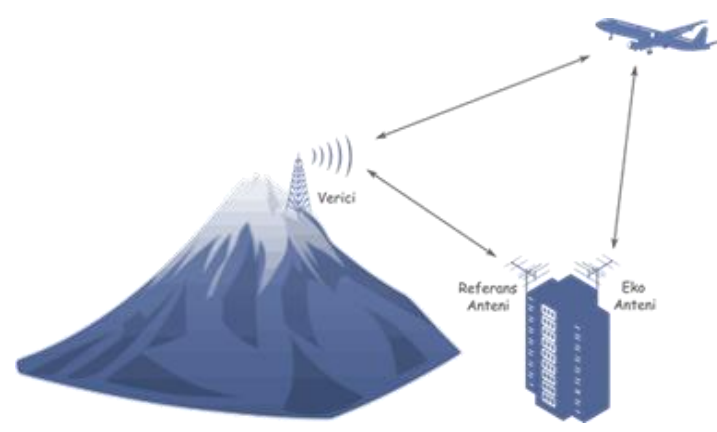

Şekil 1. Pasif radar sistemine ait temel bir geometri.

Pasif radar sistemlerinde ortamda var olan vericilere ait sinyallerin menzil ve Doppler çözünürlüğü, hedef tespit performansını belirleyen en temel unsurlardir (Zheng ve Wang, 2017). Sistemin Doppler çözünürlüğü, hedef hızına bağlı olarak integrasyon süresi arttırılarak geliştirilebilir. Menzil çözünürlüğü ise vericinin bant genişliği arttırılarak iyileştirilebilmektedir. Ancak pasif radar sistemlerinde vericiler operatörün kontrolünde olmadığından bant genişliği arttırılamamakta ve buna bağlı olarak menzil çözünürlüğü iyileştirilememektedir (Griffiths ve Baker, 2005b).

Literatürde çoklu ardışık kanalların kullanımını temel alan çalışmalar bulunmaktadır. Taşdelen ve Koymen (2006) tarafından yapılan bir çalışmada çoklu FM radyo kanallarının kullanımının menzil çözünürlüğüne etkileri incelenmiş ve olumlu sonuçlar gözlemlenmiştir. Conti vd. (2012) tarafından yapılan bir başka çalışmada ise çok kanallı DVB-T vericisi kullanılarak yüksek menzil çözünürlüğü sağlanmıştır. Lu vd. (2007) tarafından yapılan bir çalışmada ise çok kanallı GSM tabanlı bir pasif radar sistemi geliştirilmiştir. Geliştirilen bu sistem hava hedeflerinin takibinin yapılmasina olanak sağlamıştır.

$\mathrm{Bu}$ çalışmada, özellikle Wi-Fi gibi kanalların birbiri ile örtüştüğü durumlarda birden fazla kanalın birlikte kullanılmasıla menzil çözünürlüğünün iyileştirilebileceği gösterilmiştir. $\mathrm{Bu}$ amaçla ilk olarak tek kanalda benzetimi yapılan OFDM sinyal kaynağına ait öz-belirsizlik fonksiyonu incelenmiştir. Ardından ardışık çok kanal kullanılarak benzetimi yapılan OFDM sinyal kaynağına ait öz-belirsizlik fonksiyonu ve menzil çözünürlüğündeki değişimler karşılaştırılmıştır.

$\mathrm{Bu}$ makalenin 2. bölümünde öz-belirsizlik fonksiyonu hakkında bilgi verilmiştir. 3. bölümünde ise yazılım tabanlı radyo kullanarak ardışı OFDM sinyallerinin üretimi gösterilmiştir. Devamında 4. bölümünde yazılım tabanlı radyo ile 
üretilen ardışık OFDM sinyallerinin öz-belirsizlik fonksiyonu grafikleri ve bunların menzil kesiti grafiklerinin analizi yapılmıştır. Son olarak 5 . bölümünde ise sonuçlar paylaşılmıştır.

\section{2. Öz-Belirsizlik Fonksiyonu}

Radar sinyallerinin menzil ve Doppler çözünürlüğünün belirlenmesi için teorik formüllerden yararlanılabilir. Fakat pasif radar sistemlerinde firsat vericisinin modülasyon içeriğ $i$ sinyalin çözünürlügünü değiştirmektedir. $\mathrm{Bu}$ yüzden sinyalin menzil ve Doppler çözünürlügünün belirlenmesinde matematiksel bir araç olan öz-belirsizlik fonksiyonu kullanılmaktadır (Skolnik, 2007). Belirsizlik fonksiyonu Denklem (1)'de verilmiştir.

$\chi(\tau, f)=\int_{-\infty}^{\infty} s(t) s^{*}(t-\tau) e^{i 2 \pi f t} d t$

Belirsizlik fonksiyonu denkleminde incelenen sinyal $\mathrm{s}(\mathrm{t})$, zaman gecikmesi $\tau$, Doppler kayması $\mathrm{f}$ ve karmaşık eşlenik * ile ifade edilmektedir. Bu ifade ile sinyal içerisinde bulunan benzerlikler irdelenmektedir. Ĕğer sinyal kendi içerisinde benzersiz ise öz-belirsizlik grafiğinde sadece gecikmenin ve Doppler kaymasının sifir olduğu $\chi(0,0)$ noktasında bir tepe oluşması, kalan tüm noktaların sifır olmasi beklenmektedir. $\mathrm{Bu}$ durumda, ideal belirsizlik fonksiyonun şekli ters konumlandırılmış bir raptiyeye benzetilebilir. Merkezdeki bu noktanın menzil ve Doppler eksenlerindeki büyüklüğü, incelenen sinyalin menzil ve Doppler çözünürlükleri hakkında bilgi vermektedir. $\mathrm{Bu}$ çalışmada oluşturulan OFDM sinyallerinin çözünürlük analizleri için özbelirsizlik fonksiyonundan faydalanılmıştır.

\section{Yazılım Tabanlı Radyo İşlevleri}

Son y1llarda birim sinyal işleme maliyetlerinin azalması ile giderek yaygınlaşan yazılım tabanlı radyo teknolojisi, radyo sinyallerinin dirençler, kapasitörler ve geri besleme devreleri gibi analog devre elemanları yerine sayısallaştırarak işlenmesi fikrini benimsemektedir. Böylece analog devre elemanlarının kullanımı sebebiyle oluşan maliyet giderilerek sistemlere esneklik kazandırılmaktadır.
$\mathrm{Bu}$ çalışmada, öz-belirsizlik fonksiyonu incelenen OFDM sinyallerinin üretilmesi, bu sinyallerin ardışık kanallara ayrılması ve dosyalanıp işlem yapılacak bilgisayara kaydedilmesi için GNU Radio yazılımı kullanılmıştır (Bloessl vd., 2013). GNU Radio, yazılım tabanlı radyo sistemlerini gerçekleştirmek için sinyal işleme blokları sağlayan, ücretsiz, açık kaynaklı bir yazılım geliştirme araç setidir (URL-1, 2018). Aynı zamanda herhangi bir donanıma ihtiyaç duymadan kullanılabilmesi sistemlere esneklik kazandırmaktadır.

OFDM sinyallerinin GNU Radio yazılımı kullanılarak üretimi Şekil 2'de ve OFDM vericisi oluşturulması Şekil 3'te verilmektedir. Şekil 2'den görülebileceği gibi öncelikle 'Random Source' bloğu kullanılarak rastgele sinyal oluşturulmuştur. Oluşturulan sinyal 'Stream to Tagged Stream' bloğuna gönderilmiştir ve bu blok ile akışın etiketlenmesi sağlanmıştır. Burada etiketlenen sinyal 'Stream CRC32' bloğuna gönderilerek bayt akışlı sinyal elde edilmiştir. Bir sonraki aşamada ise sanal kaynaktan 'Repack Bits' bloğuna gönderilmiştir. Bu blok ile hiçbir bit kaybolmadan girdi akışın bitleri ile çıkış bitleri yeniden paketlenmiştir. Son olarak 'Tagged Stream Mux' bloğu ile her bir akış paket uzunlukları ile etiketlenmiştir ve bu bloğun çıkışında elde edilen sinyal tüm akışların uzunluk etiketlerinin toplamına sahip olan yeni bir uzunluk etiketine sahip olmuştur. $\mathrm{Bu}$ işlemler sonucunda OFDM sinyalinin üretimi tamamlanmıştır ve oluşturulan sinyal, 'Virtual Source 1' olarak OFDM vericisinin oluşturulduğu bloklar dizinine gösterilmiştir.

Sonraki aşamada 'Virtual Source 1' olarak gönderilen sinyal 'OFDM Carrier Allocator' bloğu ile OFDM vericisinde Ters Fourier Dönüşümü (IFFT) için girdi olan vektörlere dönüştürülmüştür. Aynı zamanda bu blok ile sinyalin pilot sembolleri eklenmiştir. Son olarak, 'FFT' bloğu ile Hizlı Fourier Dönüşümü (FFT) uygulanarak aralarında boşluk bırakılmış ve OFDM sinyali elde edilmiştir. Uygulanan bu işlemler sonucunda sinyal vericiden yayılan bir OFDM sinyali haline getirilmiştir. GNU Radio ile oluşturulan bu OFDM sinyali 22 $\mathrm{MHz}$ bant genişliğine sahiptir. 


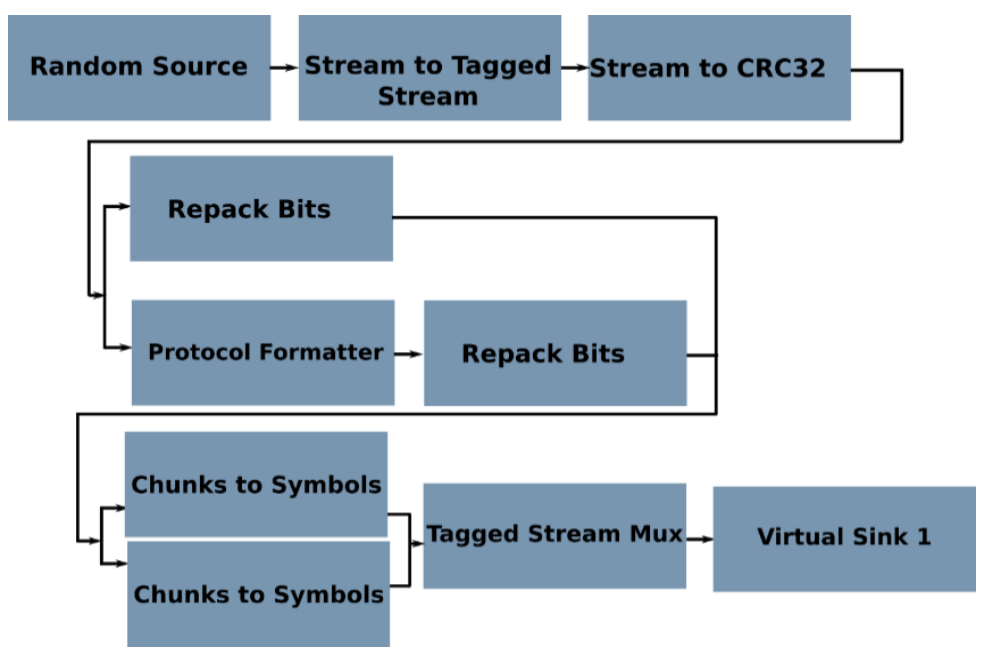

Şekil 2. OFDM sinyali üretimi GNU Radio blok diyagramı.

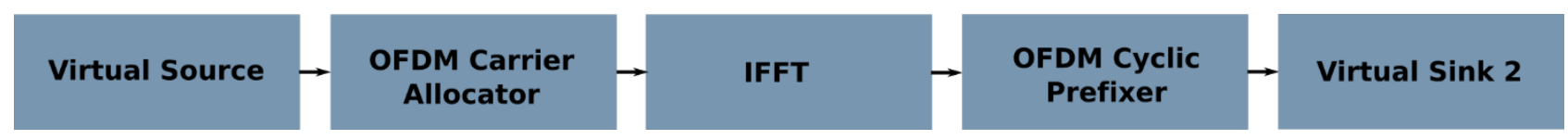

Şekil 3. OFDM vericisi GNU Radio blok diyagramı.

Oluşturulan OFDM sinyallerinin kanallara ayrılması ve dosyalanması için kullanılan GNU Radio yazılımı blok diyagramı Şekil 4'te gösterilmektedir. Burada, 'Virtual Source 2' bloğundan iletilen sinyal taşıyıcı frekansı $+5 \mathrm{MHz}$ ve taşıyıcı frekansı $-5 \mathrm{MHz}$ olan sinyal kaynaklarıyla 'Multiply' bloğu kullanılarak çarpılmıştır. Böylelikle ardışı üç kanallı OFDM sinyali üretilmiştir. Ardışık beş kanallı OFDM sinyali elde etmek için ise $10 \mathrm{MHz}$ ve $-10 \mathrm{MHz}$ frekanslara sahip sinyal kaynakları sisteme eklenerek çarpılmıştır. Ardından elde edilen OFDM sinyalleri belirlenen süre boyunca dosyalanmış ve öz-belirsizlik fonksiyonu analizlerinin yapılabilmesi için 'File Sink' bloğu kullanılarak ilgili birimde kayıt altına alınmıştır. Oluşturulan OFDM sinyallerinin WiFi sinyali olduğu varsayıldığında bu işlemler sonucunda oluşacak frekans spektrumu Şekil 5'te gösterilmektedir. $\mathrm{Bu}$ sinyallerinin, çoklu kanal ile kullanımında kanalların bant genişliği Denklem (2)'de verildiği gibi hesaplanmıştır. Buna göre tek kanalda $22 \mathrm{MHz}$ bant genişliği elde edilirken, ardışık üç OFDM kanalı kullanıldığında bant genişliği $32 \mathrm{MHz}$ olmuştur. Ardışık beş kanal kullanımında ise bant genişliği $42 \mathrm{MHz}$ olmaktadir.

Bant Genişliğ $i=2 x\left(\left(\frac{\text { Kanalsaynsı-1 }}{2}\right) x(\right.$ taşıyıcl sinyal frekansi $\left.)\right)+\left(\frac{\text { TekKanal Bant Genişlĭg } i}{2}\right)$

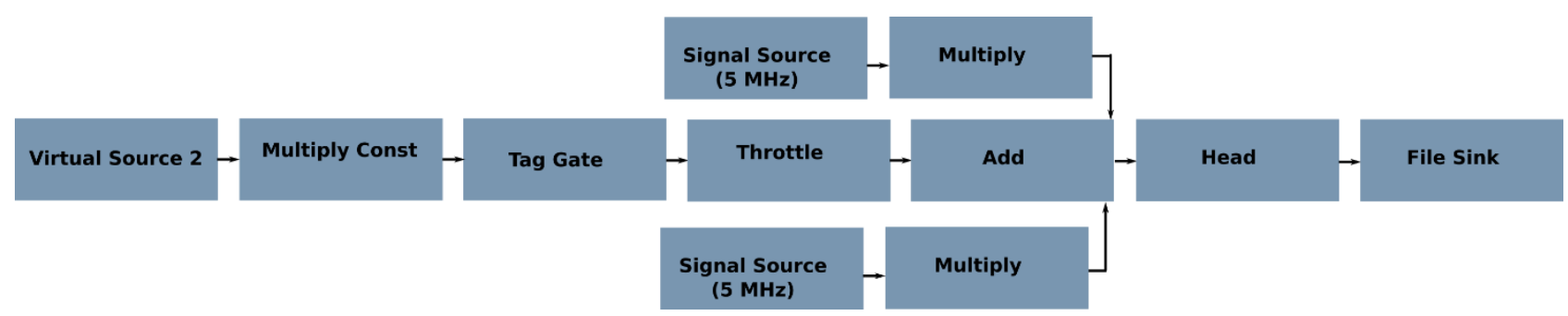

Şekil 4. Dosyalama işlemi için kullanılan GNU Radio blok diyagramı. 


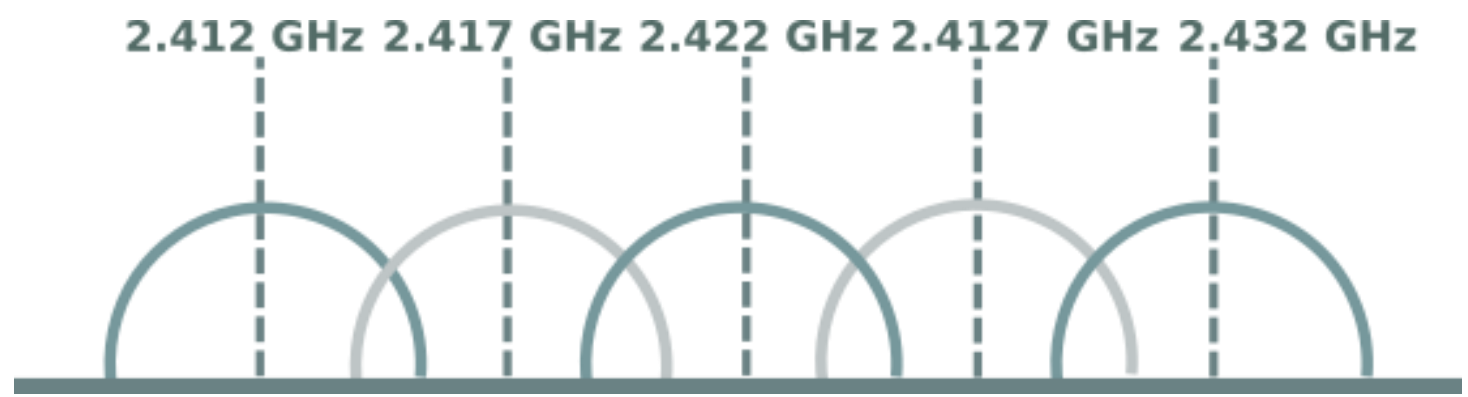

Şekil 5. Benzetimi yapılan ardışık OFDM kanallarının frekans spektrumu gösterimi.

\section{Bulgular ve Tartışma}

\section{1. Öz-Belirsizlik Fonksiyonu Analizleri}

$\mathrm{Bu}$ bölümde oluşturulan OFDM sinyallerinin özbelirsizlik fonksiyonları incelenerek menzil çözünürlükleri karşılaştırılmıştır. Tüm verilerin özbelirsizlik fonksiyonunun analizinde integrasyon zamanı 0.1 saniye olarak kullanılmıştır. İlk olarak tek kanallı bir OFDM sinyalinin öz-belirsizlik fonksiyonu incelenmiştir. Bu sinyalin 3 boyutlu öz-

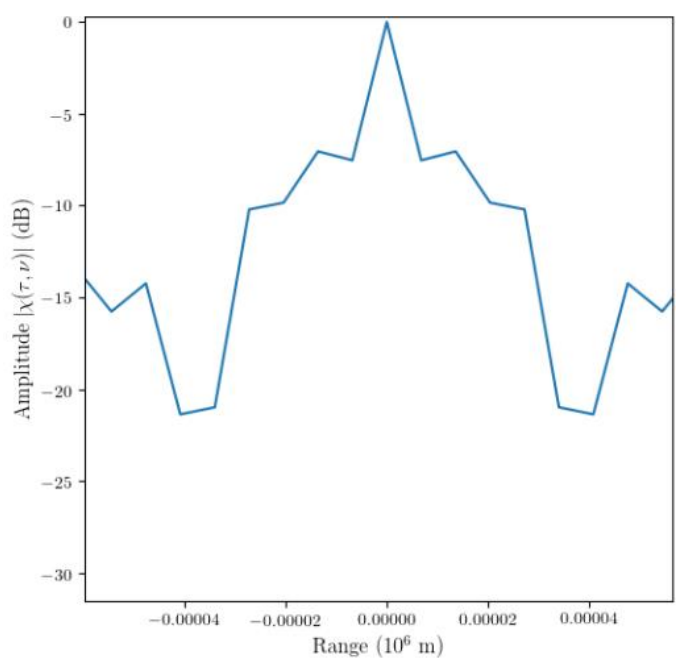

a) belirsizlik fonksiyonu grafiği ve menzil kesiti Şekil 6'da gösterilmiştir. Grafikten de görüldüğü üzere ideal belirsizlik fonksiyonu tanımında olduğu gibi $\chi(0,0)$ noktasında bir tepe oluşmuştur. Aynı zamanda beklenildiği gibi OFDM kodlama şeması nedeniyle başka pikler de oluşmuştur. Menzil kesitinden de görülebileceği gibi $22 \mathrm{MHz}$ bant genişliği ve 0.1 saniye integrasyon süresine sahip tek bir OFDM kanalı için menzil çözünürlüğü yaklaşık 35 metre olmuştur.

Şekil 6. $22 \mathrm{MHz}$ bant genişliğine sahip tek kanallı OFDM sinyallerinin 0.1 saniye integrasyon süreli öz-belirsizlik fonksiyonu grafiği. (a) Menzil kesiti. (b) Öz-belirsizlik fonksiyonu.

Ardından ardıșık üç kanallı OFDM sinyali elde etmek için tek kanallı sinyal taşıyıcı frekansı +5 $\mathrm{MHz}$ ve taşıyıcı frekansı $-5 \mathrm{MHz}$ olan sinyal kaynaklarıyla çarpılmıştır. Tek kanalda yapılan analize benzer şekilde 0.1 saniyelik integrasyon süresi için öz-belirsizlik fonksiyonu ve menzil kesiti Şekil 7'de verilmiştir. Ardışık üç kanallı OFDM sinyalinin menzil kesiti incelendiğinde $\chi(0,0)$ noktasındaki bükülmelerin tek kanallı sinyale göre azaldığı görülmektedir. Bu durumda menzil çözünürlüğü yaklașı 22 metredir. Tek kanallı OFDM sinyali ile kıyaslandığında ardışık üç kanallı sinyal kullanıldığında menzil çözünürlüğünde belirgin bir iyileşme görülmektedir. Sinyalin öz-belirsizlik fonksiyonu grafiği incelendiğinde ideal belirsizlik fonksiyonu yapısının korunduğu görülmektedir. Bununla birlikte OFDM kodlama önekleri nedeniyle yan tepeciklerin gücünde artış olduğu gözlemlenmektedir. 


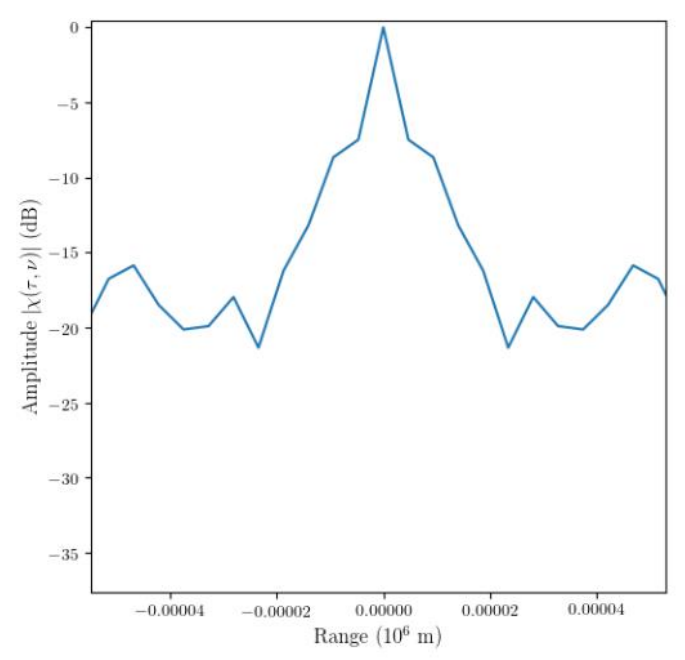

a)

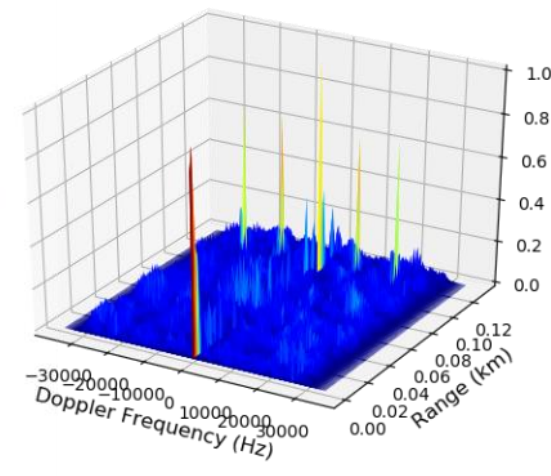

b)

Şekil 7. Ardışık üç kanallı $32 \mathrm{MHz}$ bant genişliğine sahip OFDM sinyalinin öz-belirsizlik fonksiyonu grafiği. (a) Menzil kesiti. (b) Öz-belirsizlik fonksiyonu.

Son olarak menzil çözünürlügündeki değişimleri daha iyi gözlemleyebilmek amacıyla ardışık beş kanallı OFDM sinyali ile analiz yapılmıştır. Bu durumda bant genişliği $42 \mathrm{MHz}$ 'dir. Sinyalin 0.1 saniyelik integrasyon süresi için öz-belirsizlik fonksiyonu ve menzil kesiti grafiği Şekil 8'de verilmiştir. Bu grafiğe göre menzil kesiti yaklaşık 17 metredir. Tek kanallı ve ardışı üç kanallı OFDM sinyallerin menzil kesitlerinde $-5 \mathrm{~dB},-10$ $\mathrm{dB}$ arasında görülen bükülmelerin ardışı beş kanallı OFDM sinyali kullanıldığında ortadan kalktığı görülmektedir. Tek kanallı sinyal ile

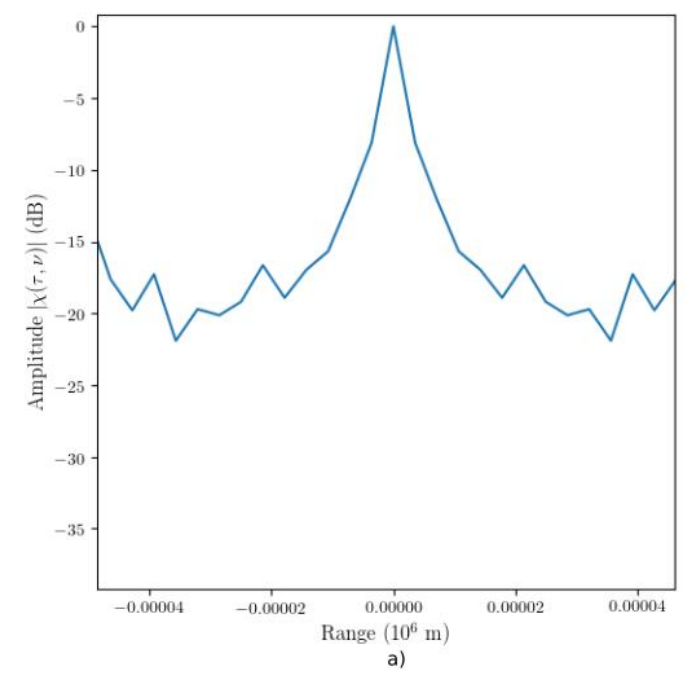

karşılaş̧ırıldığında ardışık beş kanal ile menzil çözünürlüğü yaklaşık $\% 48$ oranında iyileştirilmiştir. Aynı zamanda öz-belirsizlik fonksiyonu grafiği incelendiğinde grafiğin ters duran bir raptiyeye benzediği, ideal belirsizlik fonksiyonu yapısının korunduğu görülmektedir. Bunların yanında belirsizlik fonksiyonunda oluşan yan tepeciklerin gücünde artış oluştuğu da görülmüştür. Fakat bu oluşan yan tepeciklerin arındırılması çeşitli sinyal işleme algoritmaları kullanılarak kolaylıkla sağlanabilir (Tao vd., 2012).

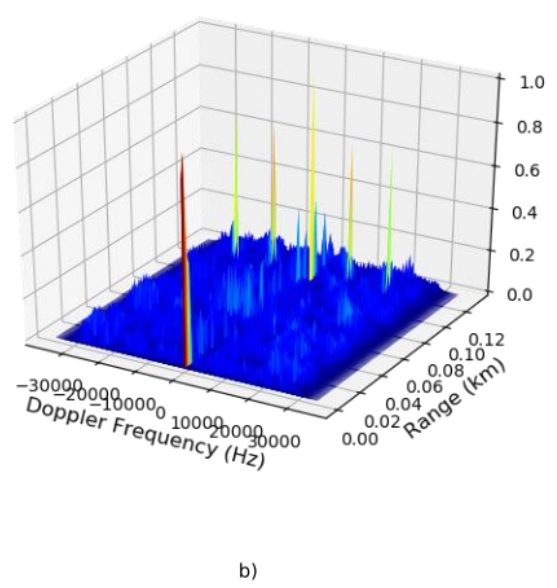

Şekil 8. Ardışık 5 kanallı $42 \mathrm{MHz}$ bant genişliğine sahip OFDM sinyalinin öz-belirsizlik fonksiyonu grafiği. (a) Menzil kesiti. (b) Öz-belirsizlik fonksiyonu.

\section{Sonuçlar}

Kablosuz vericilerin artması elektromanyetik kirliliğe neden olmakta ve frekans spektrumunu her geçen gün doldurmaktadır. Frekans spektrumunu verimli bir şekilde ayrıştırmak için bazı bilimsel yaklaşımlar vardır ancak uygulama olanakları şu anda sinırlı kalmaktadır. Bu nedenle, kablosuz vericileri başka amaçlarla çevreye yaymadan kullanmak önemlidir. Pasif radarlar bu kullanımın iyi bir örneğidir. Ancak bu tür sistemler vericinin menzil çözünürlügüne bağımlıdır. 
$\mathrm{Bu}$ çalışmada, pasif radar sistemlerinde ardışık OFDM kanalı kullanılarak sinyalin bant genişliği arttırılmıştır ve bu durumun menzil çözünürlüğüne etkileri incelenmiştir. İlk olarak bir OFDM vericisinin benzetimi yazılım tabanlı radyo kullanılarak yapılmıştır ve sinyalin menzil çözünürlüğü araştırılmıştır. Ardından ardışık OFDM kanalları eklenerek menzil çözünürlüğündeki iyileşme gözlemlenmiştir. Tek kanal, üç kanal ve beş kanallı OFDM sinyalleri kullanıldığında elde edilen menzil çözünürlükleri Tablo 1'de verilmektedir. Tek kanallı bir OFDM sinyalinin menzil çözünürlüğü Tablo 1'den de görüldüğü üzere 35 metredir. Ardışık beş OFDM kanalı kullanılarak menzil çözünürlüğünün \%48 oranında arttırabileceği görülmüsşür. Bununla birlikte OFDM kodlama önekleri nedeniyle özbelirsizlik fonksiyonunda yan tepeciklerin görülmesi beklenen bir durumdur. Yan tepecikleri temizlemek için ek sinyal işleme algoritmaları gerekmektedir.

Tablo 1. Tek kanal, ardışık üç kanal ve beş kanallı OFDM sinyalleri kullanıldığında elde edilen menzil çözünürlükleri.

\begin{tabular}{cc}
\hline $\begin{array}{c}\text { OFDM } \\
\text { Kanal Sayısı }\end{array}$ & $\begin{array}{c}\text { Menzil } \\
\text { Çözünürlüğ̈̈ }\end{array}$ \\
\hline $\mathbf{1}$ & 35 metre \\
\hline $\mathbf{3}$ & 22 metre \\
\hline $\mathbf{5}$ & 17 metre \\
\hline
\end{tabular}

Yapılan çalışma sonucunda pasif radar sistemlerinde ardışık OFDM kanalı kullanıldığında belirsizlik fonksiyonunun genel yapısına zarar verilmediği görülmektedir. Bununla birlikte pasif radar sistemlerinde ardışık OFDM kanalı kullanımı ile sistemlerin etkinliğinin arttırılabileceği ve yeni uygulama alanları kazandırılabileceği düşünülmektedir. Önerilen yaklaşım ile kısa mesafede Wi-Fi, uzun mesafede ise daha yüksek çıkış gücü sunan DVB-T gibi OFDM tabanlı verici yayınları kullanılarak çözünürlügüne bağlı olarak yakın menzillerde bulunan çoklu hedeflerin birbirinden ayrıştırılması sağlanabilir.

\section{Kaynaklar}

Berger, C. R., Demissie, B., Heckenbach, J., Willett, P. ve Zhou, S., 2010. Signal Processing for Passive Radar Using OFDM Waveforms. IEEE Journal of Selected Topics in Signal Processing, 4(1), 226-238.

Bloessl, B., Segata, M., Sommer, C. ve Dressler, F., 2013. An IEEE $802.11 \mathrm{a} / \mathrm{g} / \mathrm{p}$ OFDM Receiver for GNU Radio. In Proceedings of the Second
Workshop on Software Radio Implementation Forum, 9-16.

Brisken, S., Moscadelli, M., Seidel, V. ve Schwark, C., 2017. Passive Radar Imaging Using DVB-S2. In Radar Conference (RadarConf), 2017 IEEE, 0552-0556.

Colone, F., Falcone, P., Bongioanni, C. ve Lombardo, P., 2012. WiFi-Based Passive Bistatic Radar: Data Processing Schemes and Experimental Results. IEEE Transactions on Aerospace and Electronic Systems, 48(2), 1061-1079.

Conti, M., Berizzi, F., Martorella, M., Dalle Mese, E., Petri, D. ve Capria, A., 2012. High Range Resolution Multichannel DVB-T Passive Radar. IEEE Aerospace and Electronic Systems Magazine, 27(10), 37-42.

Griffiths, H. D. ve Baker, C. J., 2005a. Passive Coherent Location Radar Systems. Part 1: Performance Prediction. IEE Proceedings-Radar, Sonar and Navigation, 152(3), 153-159.

Griffiths, H. D. ve Baker, C. J., 2005b. Measurement and Analysis of Ambiguity Functions of Passive Radar Transmissions. In Radar Conference, 2005 IEEE International, pp. 321-325.

Lauri, A., Colone, F., Cardinali, R., Bongioanni, C. ve Lombardo, P., 2007. Analysis and Emulation of FM Radio Signals for Passive Radar. In Aerospace Conference, 2007 IEEE, pp. 1-10.

Lu, Y. L., Tan, D. K. P. ve Sun, H. B., 2007. Air Target Detection and Tracking Using a Multi-channel GSM Based Passive Radar. In Waveform Diversity and Design Conference. pp. 122-126.

Milani, I., Colone, F., Bongioanni, C. ve Lombardo, P., 2018. WiFi Emission-Based vs Passive Radar Localization of Human Targets. In Radar Conference (RadarConf18), 2018 IEEE, 13111316.

Skolnik, M. I., 1962. Introduction to radar. Radar handbook, 2, McGraw-Hill. Boston, 15p.

Stein, S., 1981. Algorithms for Ambiguity Function Processing. IEEE Transactions on Acoustics, Speech, and Signal Processing, 29(3), 588-599.

Tao, R., Gao, Z. ve Wang, Y., 2012. Side peaks interference suppression in DVB-T based passive radar. IEEE Transactions on Aerospace and Electronic Systems, 48(4), 3610-3619.

Tasdelen, A. S. ve Koymen, H., 2006. Range Resolution Improvement in Passive Coherent Location Radar Systems Using Multiple FM Radio Channels. IET Forum on Waveform Diversity and Design in Communications, Radar and Sonar, 23-31. 
Tüysüz, B., Urbina, J. ve Lind, F. D., 2013. Development of a Passive VHF Radar System Using Software-Defined Radio for Equatorial Plasma Instability Studies. Radio science, 48(4), 416-426.

Tüysüz, B. ve Mahmutoglu, Y., 2017. Measurement and Mapping of the GSM-Based Electromagnetic Pollution in the Black Sea Region of Turkey. Electromagnetic biology and medicine, 36(2), 132-140.
Tüysüz, B., 2018. Hava Hedeflerinin Tespiti İçin Yakın Gerçek Zamanlı Çoklu Frekans Destekli Pasif Radar Sisteminin Geliştirilmesi. Gazi Üniversitesi Mühendislik-Mimarlık Fakültesi Dergisi, 34(1), 191-200.

URL-1, http://www.gnuradio.org/. 24 Kasım 2018.

Zheng, L. ve Wang, X., 2017. Super-Resolution DelayDoppler Estimation for OFDM Passive Radar. IEEE Transactions on Signal Processing, 65(9), 2197-2210. 